\title{
UNMANNED AERIAL VEHICLE \\ SURVEYING FOR MONITORING ROAD CONSTRUCTION EARTHWORKS
}

2019/14(1)

\author{
KALEV JULGE ${ }^{1,2^{*}}$, ARTU ELLMANN'1, ROMET KÖÖK¹ \\ ${ }^{1}$ Dept of Civil Engineering and Architecture, School of Engineering, \\ Tallinn University of Technology, Tallinn, Estonia \\ ${ }^{2}$ Reach-U AS, Tartu, Estonia
}

Received 03 September 2018; accepted 14 November 2018

\begin{abstract}
Unmanned aerial vehicle photogrammetry is a surveying technique that enables generating point clouds, 3D surface models and orthophoto mosaics. These are based on photos captured with a camera placed on an unmanned aerial vehicle. Within the framework of this research, unmanned aerial vehicle photogrammetry surveys were carried out over a sand and gravel embankment with the aim of assessing the vertical accuracy of the derived surface models. Flight altitudes, ground control points and cameras were varied, and the impact of various factors on the results was monitored. In addition, the traditional real-time-kinematic Global Navigation Satellite System surveys were conducted for verifications. Surface models acquired by different methods were used to calculate volumes and compare the results with requirements set by Estonian Road Administration. It was found that with proper measuring techniques an accuracy of $5.7 \mathrm{~cm}$ for the heights were achieved.
\end{abstract}

Keywords: accuracy assessment, photogrammetry, road construction, surface models, unmanned aerial vehicle (UAV).

\footnotetext{
* Corresponding author. E-mail: kalev.julge@taltech.ee 


\section{Introduction}

The movement of large volumes of the earth (earthworks) is an essential part of road construction. It requires a considerable amount of engineering effort and road construction equipment. The planning, scheduling, and supervising of earthworks operations are of importance in obtaining economically feasible solutions. Earthworks computations involve the calculation of volumes or quantities, the determination of final slopes, balancing of cuts and fills, and the planning of the most economical haul of material. For this, a number of surveying points at the slope of break lines of the progressing road embankment are selected, and their 3D coordinates (horizontal position and height) need to be determined. Such an as-built survey is conducted routinely during the construction several times. Nowadays the surveyor uses a combination of Global Navigation Satellite Systems (GNSSs) and robotic total station surveying methods when assessing the earthworks and set out for the excavation and placement of material. Such traditional surveys are simple but time-consuming and laborious. In addition, the pointwise selection often yields omission errors due to surface unevenness in-between the consecutive survey points (Sobak, Ellmann, \& Mill, 2015). Hence, alternative methods for semi-automatic assessment of the earthworks are necessary.

Modern remote sensing technology has become more accessible to the surveying community. In particular, unmanned aerial vehicle (UAV) photogrammetry is a relatively novel but rapidly developing surveying method. Photogrammetry is used for taking measurements from photographs, especially for reconstructing the geometry of a surface. Within the surveying industry, the UAV photogrammetry has gained popularity as a fast, cheap and flexible surveying method for generating orthophoto mosaics, point clouds and 3D models of topographic features (Pajares, 2015). This technique has been described in detail by Carrivick, Smith, \& Quincey (2016), Colomina \& Molina (2014), Nex \& Remondino (2014), and Westoby, Brasington, Glasser, Hambrey, \& Reynolds (2012) have reviewed the use of UAVs in topographical mapping. Unmanned aerial vehicle photogrammetry has been used in mapping surface deformations in fields such as glaciology (Bhardwaj, Sam, Martín-Torres, \& Kumar, 2016) and landslide monitoring (Fernández, Pérez, Cardenal, Gómez, Colomo, \& Delgado, 2016; Turner, Lucieer, \& De Jong, 2015), as well as monitoring open pit mines (Chen, Li, Chang, Sofia, \& Tarolli, 2015; Rossi, Mancini, Dubbini, Mazzone, \& Capra, 2017; Tong, Liu, Chen, Luan, Li, ... \& Hong, 2015) and stockpiles (Raeva, Filipova, \& Filipov, 2016).

Intuitively, road engineering can also benefit from the UAV surveys. For instance, UAV photogrammetry is used to generate a 
detailed model before and after each construction stage to determine earthwork quantities. It notes that UAV merely a platform, which needs to be powerful enough to lift the camera payload and fly along a predetermined trajectory. Unmanned aerial vehicles that carry heavier payloads are mounted with better quality cameras. Cost-effective implementation of UAV surveying requires that field operations are planned to acquire sufficient spatial data efficiently, and that data processing can filter out non-ground points to provide an accurate "bare earth" model (Julge, Ellmann, \& Gruno, 2014). There is evidence that the governmental road administration authorities have innovatively started to encourage the usage of UAV-based monitoring of roadwork. For instance, the Estonian Road Administration requested in public procurement for owner supervision of road engineering roadwork the usage of UAV photogrammetry (Estonian Road Administration, 2018). The required accuracy for the UAV photogrammetry performance was specified to be $5 \mathrm{~cm}$ (in the height component). Accordingly, this research aims to analyse the suitability of low-cost UAV photogrammetry for monitoring earthworks at road construction sites and the feasibility of the accuracy above requirement. Two UAV platforms were tested - one very basic, cheap and easy-to-use, and another one of much higher quality, but more expensive. The study area comprises of a road embankment with steep slopes. The results from UAV photogrammetry were compared to reference data gathered with a geodetic GNSS receiver. In addition, the effect of different flight heights and the number of needed ground control points (GCPs) was analysed.

The outline of the paper is as follows. First, the study area is described along with the description of the reference data. After that, the specifications of the used UAVs and cameras are presented, as well as the description of the UAV campaigns. Then the results are presented and analysed. The recommendations for conducting UAV-based earthwork volume surveys are outlined. A summary concludes the paper.

\section{Theoretical background of unmanned aerial vehicle photogrammetry accuracy and principles of volume estimations}

The accuracy of UAV photogrammetry depends on many factors - the quality of the photographs, the characteristics of the measured surface, the placement of GCPs, overlap of the photos, flight height. Generally, providing a proper methodology in fieldwork and data processing has been followed, the accuracy of photogrammetry products is estimated 
to be about 2-3 times of the ground sampling distance (GSD) (Barry \& Coakley, 2013). Ground sampling distance is the distance between two neighbouring pixel centres of the image measured on the ground. Larger GSD decreases the spatial resolution of the image, accordingly the details become less visible. Properties of the camera sensor and flight height influence the GSD (the higher the flight, the larger the corresponding GSD value).

Required flight height $H$ (in the units of $\mathrm{m}$ ) required for obtaining a given GSD is calculated based on the camera focal length, the camera sensor width and the image width as:

$$
H=\frac{G \cdot i m W \cdot F r}{S w \cdot 100},
$$

where $G$ - denotes desired GSD, cm/pixel; imW - image width, pixels; $\mathrm{Fr}$ - real focal length, $\mathrm{mm}$; $\mathrm{Sw}$ - denotes real sensor width, $\mathrm{mm}$.

Unmanned aerial vehicle surveys performed before and after each stage of construction reveal the volume of earthworks. First, a reference surface is generated based on the survey conducted before the earthworks started. After the earthworks have finished, the situation is surveyed again, and a new surface model is generated for the terminated stage. Generally, Triangulated Irregular Network (TIN) models or raster Digital Elevation Models (DEM) are used. The earthwork quantities are calculated by comparing the two (sequential) surface models and calculating volumes by using the grid method, triangular prisms or cross-section method.

1. The grid method involves dividing the area into square-shaped cells of equal size. Within these grid cells, the average height of both the reference and new surface are found. Based on these values the depth of cut or fill in each cell are calculated. By multiplying the depth $(d)$ and the cell area $(A)$, volume $(V)$ of each cell is determined by $V=d \cdot A$. Summing the volumes of all the cells results in the total cut and fill volumes of the earthworks.

2. The triangular prisms method is the most accurate and technically advanced method for calculating earthworks volumes. First, TIN models of both the reference and new surface are calculated. After that, the two TINs are merged to create a third TIN. This TIN contains all the details from the original TINs and is used in the calculations. Next, the cut and fill at each vertex on the merged TIN is calculated. Based on these values the cut and fill for each triangle is found. By adding all values of the cut and fill together, the total cut and fill volumes of the earthworks are determined. 
3. The cross-section method involves generating cross-sections Unmanned Aerial Vehicle Surveying of both the reference and new surface - these need to cover the study area at regular intervals. The cut and fill areas of each for Monitoring Road Construction cross-section are determined. The volume among every sectionpair is estimated by multiplying the average cut or fill area of the two sections by the distance among them. The total cut and fill volumes are calculated by adding all these together.

The triangular prisms method is used in the empirical tests over a study area in Central Estonia.

\section{Study area and ground control points}

The study area was a roughly $40 \mathrm{~m}$ wide and $200 \mathrm{~m}$ long road construction test site near the village of Võõbu, Central Estonia. The Estonian Road Administration initiated a study for evaluating different methods for roadbuilding over peat fields without excavating the peat. Different road construction scenarios were tested. Accordingly, the test site consist of six different road foundation structures as follows: mass replacement (denoted by 0 in Figure 1), one- and two-layers geotextile reinforcement (denoted by 1 and 2 in Figure 1), geocell structure (denoted by 3 in Figure 1), lightweight aggregate (denoted by 4 in

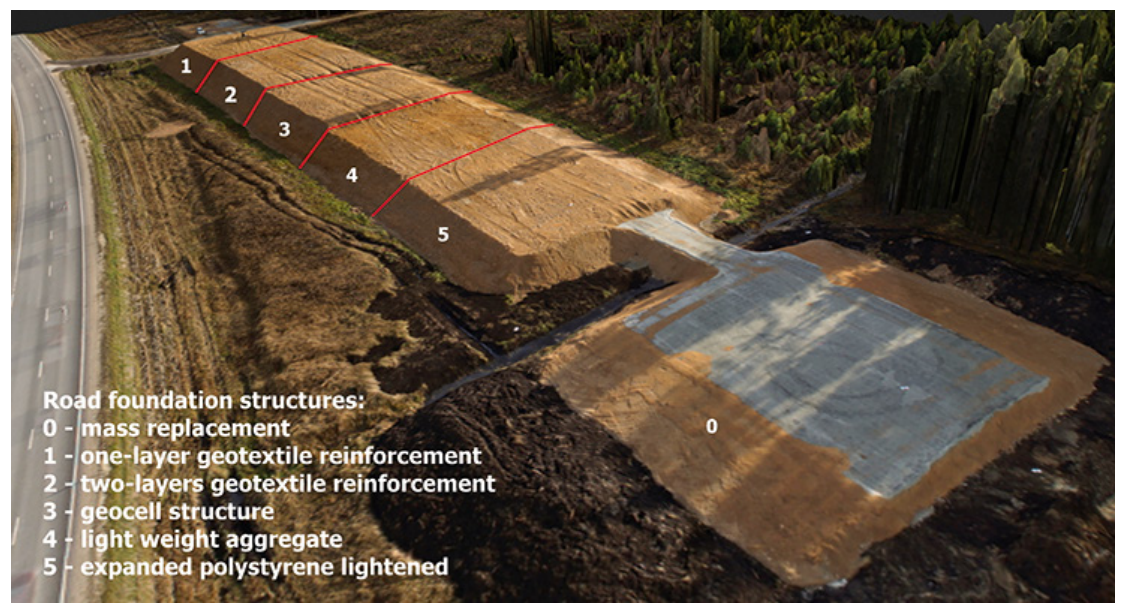

Note: steps on the surface of the embankment; the existing Tallinn-Tartu two-lane highway is on the left-hand side of the image.

Figure 1. 3D model of the Võõbu test site embankment (volume $\sim 17000 \mathrm{~m}^{3}$ ), compiled from the unmanned aerial vehicle surveying 
Figure 1) and expanded polystyrene lightened embankment structures (denoted by 5 in Figure 1). The reinforced test sections were loaded with gravel surcharge mass (also of varying thickness, from $0.5 \mathrm{~m}$ up to $2.2 \mathrm{~m}$ ) to accelerate the consolidation of the peat layer (the initial thickness of it varied from $2 \mathrm{~m}$ to $4 \mathrm{~m}$ ). A more detailed description of the constructed test structures and geotechnical aspects are found in a study by Forsman, Dettenborn, Skepast, Mets, Olep, Ellmann, ... \& Kontson (2016). The resulting embankment was measured by UAV photogrammetry to evaluate the accuracy of surface models and volume calculations.

Thirteen GCP ground markers were evenly distributed over the test site. These were coordinated with GNSS measurements at the same time as positioning the volume survey points (i.e. using the same GNSS initialisation, for more details - Section 4.1). The number of GCPs used in the data processing were varied to determine estimates for sufficient numbers of GCPs at UAV volume surveys.

\section{Unmanned aerial vehicle campaigns}

Two multirotor type UAVs were tested. The first is a small, widely distributed, low-cost and easy-to-use UAV mainly intended for aerial photography and videography by enthusiasts and hobbyists. However, it is used for photogrammetry as well. The second UAV is a big octocopter (8 rotors) that carries a heavier payload (Table 1). In this study, it is carrying a wide-angle lens mirrorless digital camera that captures higher quality photographs than the integrated camera on the smaller UAV. However, this UAV is about ten times more expensive than and not as straightforward to operate as the robust basic UAV. The UAV platforms are pictured in Figure 2.

Table 1. Parameters of the used unmanned aerial vehicle platforms

\begin{tabular}{|c|c|c|c|}
\hline Parameter & Unit & Octocopter & Basic \\
\hline Weight & $\mathrm{kg}$ & 4.2 & 1.24 \\
\hline Maximum payload & $\mathrm{kg}$ & 5 & 1 \\
\hline Maximum flight time & $\min$ & $15-20$ & $20-25$ \\
\hline Lens & & wide-angle & "fisheye" \\
\hline Focal length & $\mathrm{mm}$ & 16 & 5 \\
\hline Resolution & pixels & $4000 \times 6000(24 \mathrm{MP})$ & $4384 \times 3288(14.4 \mathrm{MP})$ \\
\hline Flight height & $\mathrm{m}$ & 100 & 60 \\
\hline Number of photographs taken & piece & 24 & 51 \\
\hline Ground sampling distance & $\mathrm{cm}$ & 2.4 & 2.0 \\
\hline
\end{tabular}




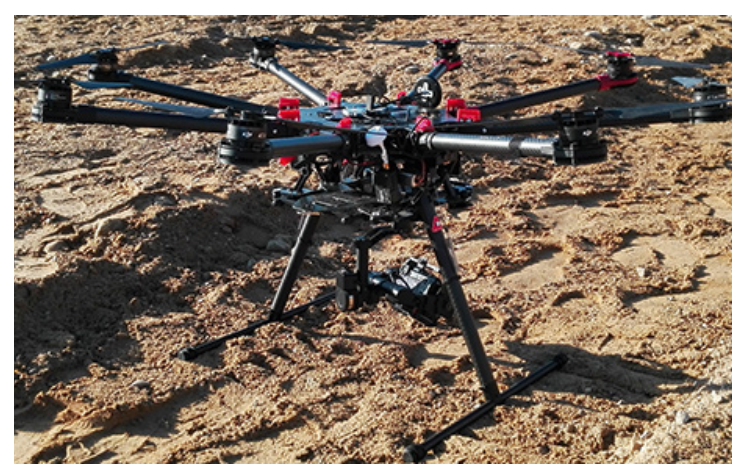

a) a big octocopter carrying

a mirrorless wide-lens camera

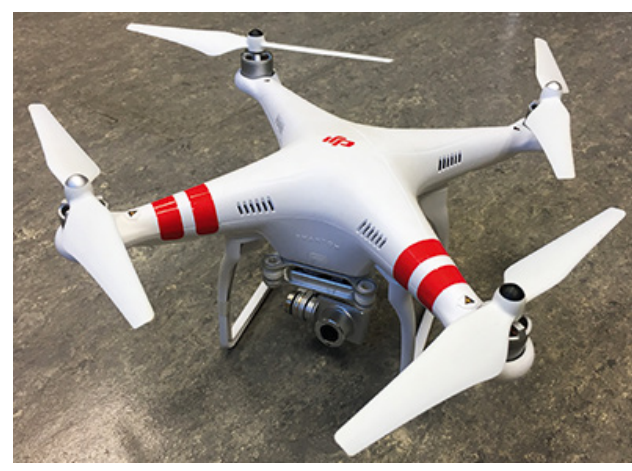

b) basic consumer unmanned aerial vehicle with integrated "fisheye" lens camera

Figure 2. The unmanned aerial vehicle used in this study

Three missions were flown over the study area in the same day - two with the octocopter at a flight height of $60 \mathrm{~m}$ and $100 \mathrm{~m}$ and one with basic UAV at a flight height of $60 \mathrm{~m}$. The main parameters of the UAVs and the flight missions are outlined in Table 1.

A flight planning software computed the flight trajectories, and the flights were conducted autonomously apart from manual takeoffs and landings. The flight trajectories and placement of the GCPs are illustrated in Figure 3. The data processing enabled obtaining dense point clouds, orthophoto mosaics and surface models. These surface models were compared, and the results were analysed.

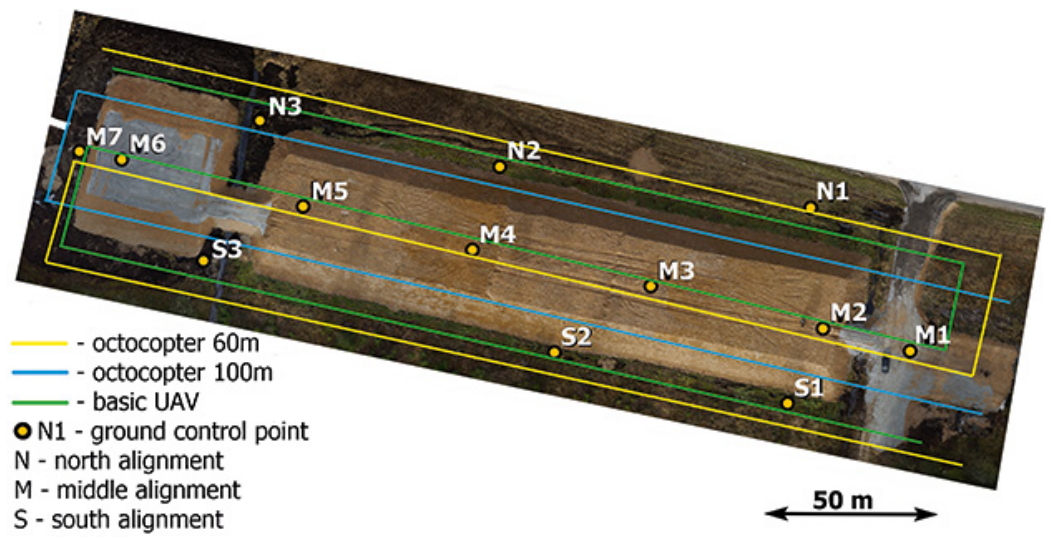

Figure 3. Flight trajectories of the unmanned aerial vehicle campaigns with the locations of the ground control point 


\section{Results}

In this section, the results achieved with UAV photogrammetry are compared with GNSS reference data. In addition, the results from different UAVs and cameras are compared to each other. The effect of flight height is analysed, as well as the necessary amount of GCPs. Finally, the results of the volume calculation are presented.

\subsection{Comparison of the Global Navigation Satellite System reference data}

The real-time kinematic (RTK) GNSS positioning of the GCP and the volume survey points (reference data) was conducted by using a GPS/GLONASS Trimble R8 receiver and a VRS (Virtual Reference Station) service provided via data-link by a commercial CORS (Continuously Operating Reference Stations) network. The stated elevation accuracy for the GNSS device is $2 \mathrm{~cm} \pm 1 \mathrm{ppm}$. Due to favourable GNSS-surveying conditions, the estimated horizontal and vertical accuracy of the positioning is $2-3 \mathrm{~cm}$. The real-time kinematic GNSS is widely used by surveyors for measuring earthworks during road construction. Overall, 196 GNSS points were measured at the characteristic points of the embankment, e.g. edges of the slopes. The distance between points did not exceed $15 \mathrm{~m}$. Based on the GNSS points digital elevation model (DEM) was constructed (Figure 4).

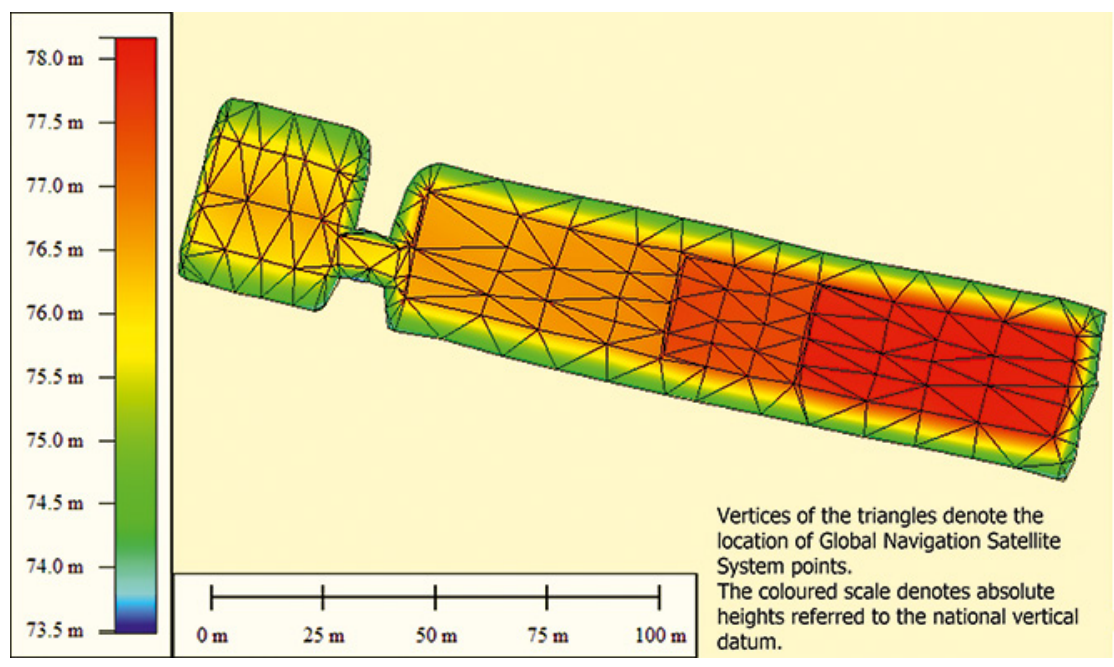

Figure 4. Digital Elevation Model of the study area derived from Global Navigation Satellite System reference points 
The results achieved with UAV photogrammetry were compared to the GNSS reference data. The comparisons for both UAVs (flight height 60m) are illustrated in Figure 5. The most considerable differences are located on the slopes of the embankment. The main reason is that the GNSS points were measured only at the bottom and top of the embankment. This measurement technique was intentionally conducted, similarly to the usual surveying practice. The slopes of the resulting GNSS surface model are (erratically) straight and flat, whereas in reality the slopes

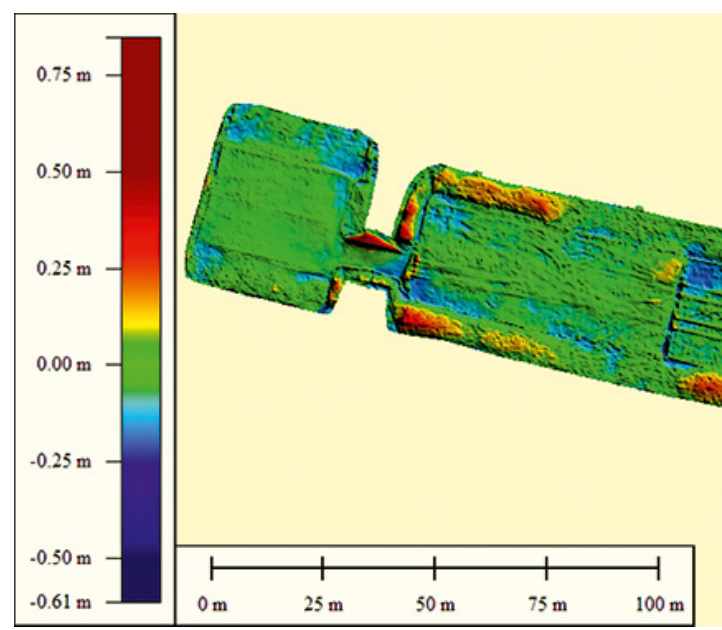
discrepancies. Red areas denote locations where Global Navigation Satellite System reference data is higher than the UAV surface model.

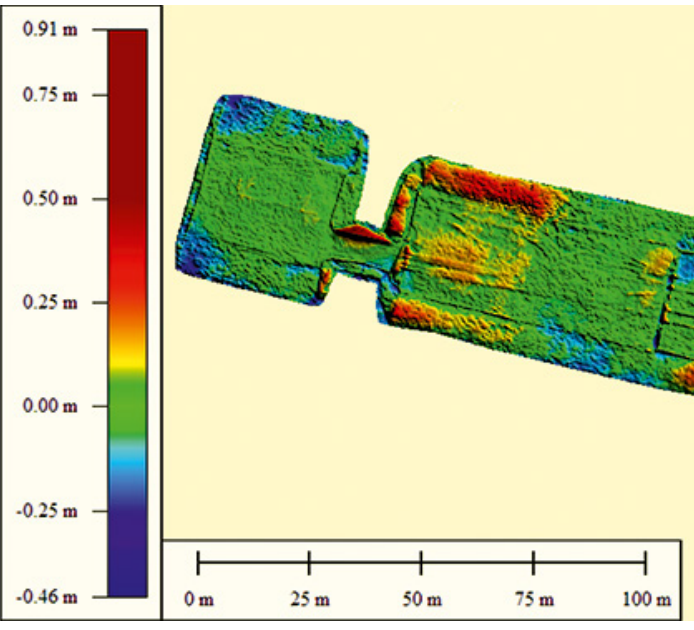

The coloured scale denotes vertical discrepancies. Red areas denote locations where Global Navigation Satellite System reference data is higher than the UAV surface model.
Unmanned Aerial Vehicle Surveying for Monitoring

Road Construction Earthworks

a) octocopter

Note: flight height of $60 \mathrm{~m}$.

Figure 5. Comparisons of unmanned aerial vehicle surface models and Global Navigation Satellite System reference data 
are concaved. This flat surface model also explains the visibility of truck trails on the top of the embankment in the comparison between GNSS and UAV model (Figure 5). Secondly, on steep slopes, the errors in planar coordinates influence vertical differences more than on the relatively flat ground. Lastly, on steep slopes, more shadows negatively affect the quality of a photogrammetry model, see also Section 4.3.

The results agree with reference data well near GCPs (Figure 3), and the differences increase further away from GCPs. Smaller differences are due to the different level of detail between UAV photogrammetry and GNSS surface models. With UAV photogrammetry the whole study area is covered. With GNSS only a limited amount of points are measured, which means the finer surface details remain unnoticed. Hence, the UAV surveys provide more adequate volume estimates than the traditional point-wise surveys.

Overall, as expected, the octocopter results are much higher quality. The more sophisticated wide-angle camera captures higherquality photographs than the camera on the basic drone. The root mean square error (RMSE) of the vertical discrepancies between UAV photogrammetry surfaces and GNSS points was $5.7 \mathrm{~cm}$ for the octocopter (which is roughly three times the GSD) and $11.2 \mathrm{~cm}$ for the basic UAV. Hence, the $5 \mathrm{~cm}$ vertical accuracy for UAV surveys is obtainable with sophisticated equipment (the high-quality camera being the most decisive one).

Based on the comparison to reference data, the quality of the camera influences the achieved results. With a higher-quality camera, it is possible to generate more accurate 3D models. The effect of different cameras is evaluated and compared in the next section.

\subsection{Impact of using different cameras and unmanned aerial vehicle platforms}

The results from different UAV platforms and cameras were compared to each other (Figure 6). The maximum number (13) of GCPs were used in both cases. The RMSE of the differences was $8.8 \mathrm{~cm}$. The differences were both negative and positive; however, at places, e.g. road sections 1,2 , and 5 (Figure 6), there are systematic shifts between the surface models. Overall, the detected differences were quite significant, even though the flight heights $(60 \mathrm{~m})$ and the number of photos (51 and 54) taken were similar. The significant differences are due to the circumstance that the digital camera on the octocopter is of better quality and captures higherquality photos with a better GSD than with the "fisheye" lens. Photos captured with the integrated camera of the basic drone also suffered from distortions caused by the "fisheye" type of lens. 


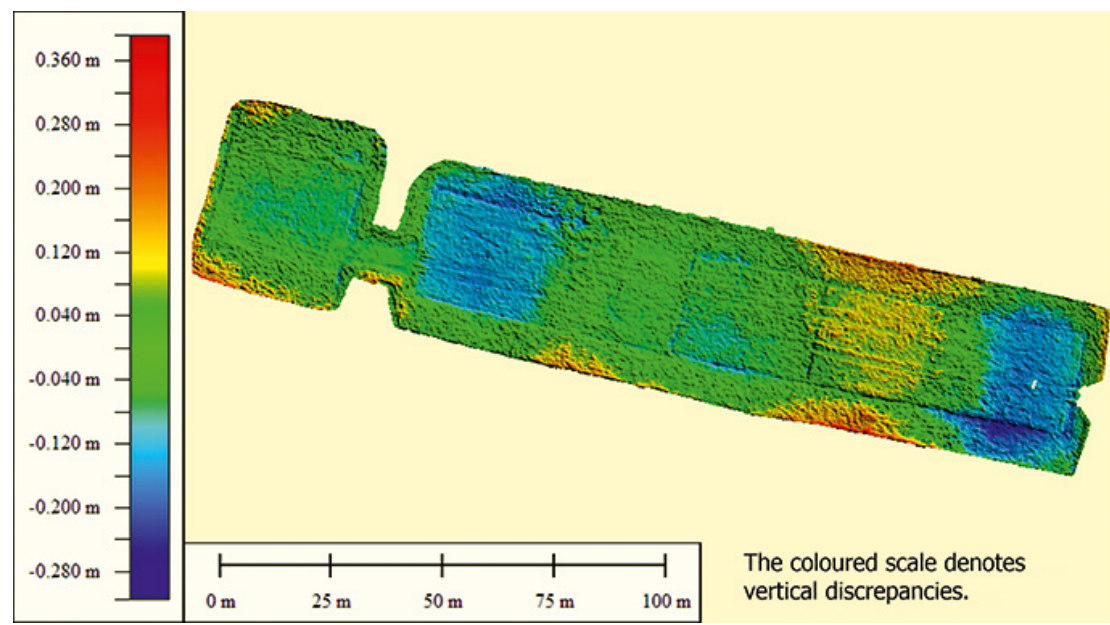

Note: flight height of both at $60 \mathrm{~m}$.

Figure 6. Comparison of the unmanned aerial vehicle surface models derived from octocopter and basic unmanned aerial vehicle data

The most decisive (regarding accuracy achievement) piece of equipment is the camera in UAV photogrammetry. The unmanned aerial vehicle is merely a platform that needs to be powerful enough to lift the camera payload and fly along a predetermined trajectory.

\subsection{Impact of different flight heights}

The effect of flight height is illustrated with a comparison of UAV photogrammetry surface models based on octocopter data captured from $60 \mathrm{~m}$ and $100 \mathrm{~m}$ flight heights (Figure 7). The maximum number (13) of GCPs were used in both cases. With a higher flight height, it is possible to cover a larger area. However, at the same time, GSD is reduced. In the comparison (using more than 3 million model points altogether), no systematic shifts were detected. The discrepancies were generally within $2 \mathrm{~cm}$, and the RMSE was $2.1 \mathrm{~cm}$. With a higher flight height and larger GSD, the level of detail is reduced. Therefore, the significant discrepancies appeared at the locations of truck trails and the edges of the sections with elevation differences (encircled in red (Figure 7)).

Other differences (encircled in blue (Figure 7)) were caused by the shadows of trees that were present during the $100 \mathrm{~m}$ flight height campaign. The $60 \mathrm{~m}$ flight height campaign was conducted with cloud cover, and no shadows were present. Therefore, the ideal conditions for 


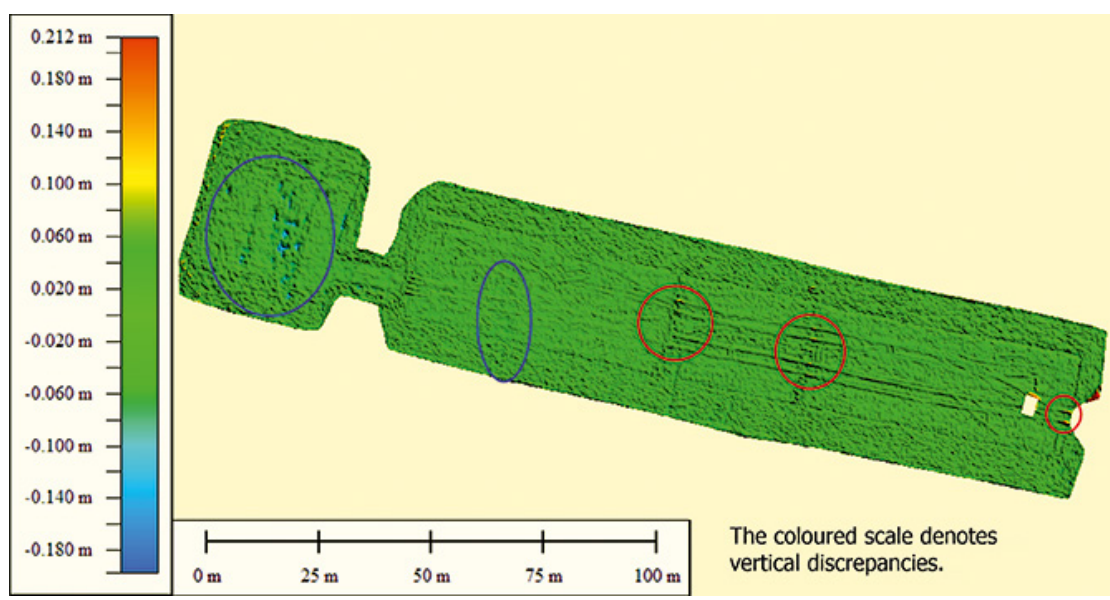

a) flight heights of $60 \mathrm{~m}$ and $100 \mathrm{~m}$

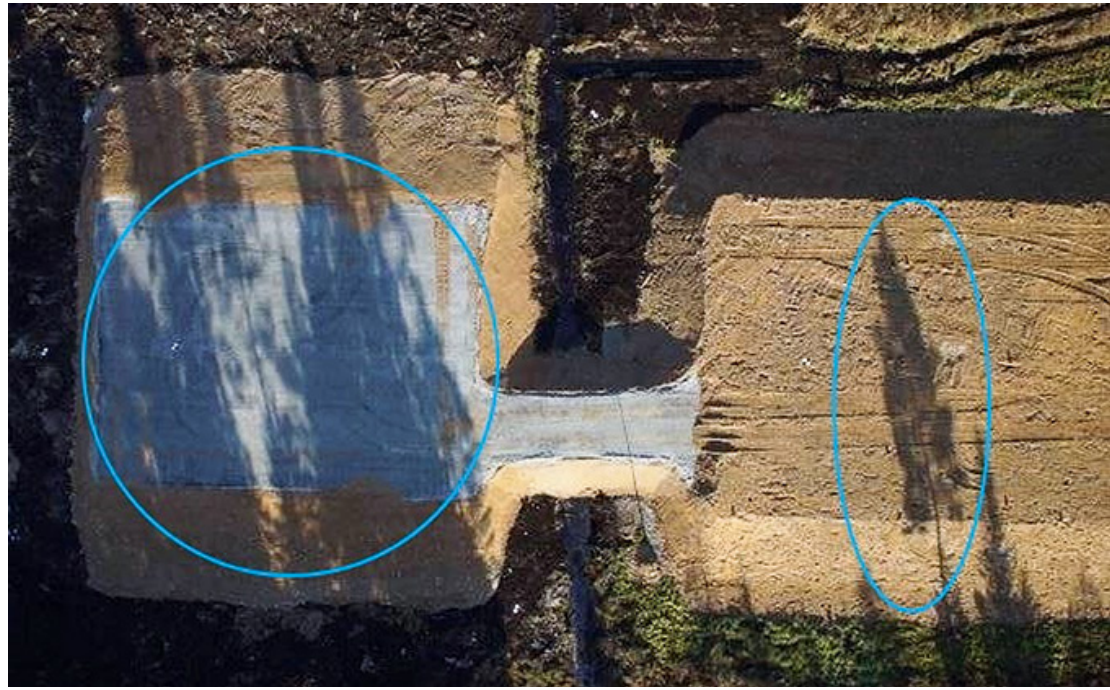

b) shadows of trees that were present during the $100 \mathrm{~m}$ flight height campaign

Figure 7. Comparison of the unmanned aerial vehicle surface models

conducting UAV photogrammetry campaigns are with cloud cover but with enough available light to capture high-quality photos.

Flight height affects the GSD and the level of detail of the subsequent model. It does not create any systematic shifts. Increasing the flight height enables covering larger areas. Although the accuracy and quality of the model decrease, this is acceptable in applications with less strict requirements. 


\subsection{Number of the ground control points}

A surface model was calculated based on only four GCPs to illustrate the importance of GCPs, and compared to the surface model that utilised all the 13 GCPs (Figure 8). Note that the usage of four GCP (with a longitudinal spacing of 150 meters) is clearly below the reasonable limit for such a road stretch. Theoretically, three GCPs are requested minimum for obtaining a formal georeferencing solution for a UAV photogrammetry model. However, the case of using four GCPs (located unreasonably distant from each other) yields an "umbrella" shape surface model. In between the GCPs, the deficient model is up to $30 \mathrm{~cm}$ higher and outside of the GCPs $20 \mathrm{~cm}$ lower than the 13 GCP based surface model. The RMSE between the surfaces is $15.2 \mathrm{~cm}$, which is a significant value considering that the used photos were identical. Therefore, using a sufficient number of evenly distributed GCPs is vital for producing good quality UAV photogrammetry products.

The placement of GCPs shown in Figure 3 is considered optimal, with the whole study area evenly covered with GCPs. It is essential to distribute GCPs both on top and at the foot of the embankment. Some stationary GCPs need to be placed on both sides of the embankment outside of the work zone. Otherwise, it is necessary to georeference all of the GCPs again. These need be prepared in an excessive amount to

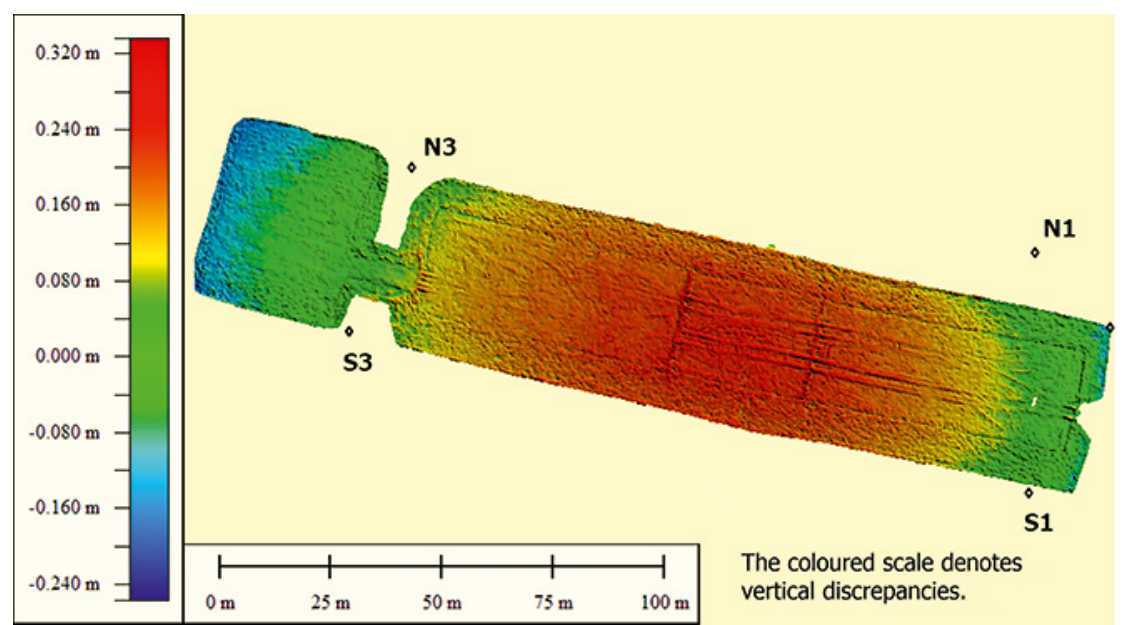

Note: octocopter data at a flight height of $60 \mathrm{~m}$

Figure 8. comparison of the unmanned aerial vehicle surface models calculated with all the ground control points and only four ground control points (S1, S3, N1, N3)
Unmanned Aerial Vehicle Surveying for Monitoring Road Construction Earthworks 
account for some of the GCPs being destroyed or blocked by construction machines during the UAV surveys. However, some GCPs in the work zone (on top of the embankment) are still be required in every measurement campaign.

\subsection{Volume calculations}

The embankment volumes were calculated by generating a ground surface based on the outline of the embankment measured with GNSS device and using that as the reference surface. All the other surface models were compared to this surface, and the volumes were calculated (Table 2). Even though the results in Table 2 suggest that the best results are achieved with the basic UAV, then this is most probably not the case. As demonstrated previously, the surface models from the basic UAV data are lower quality. Therefore, this good agreement in volumes is due to negative and positive discrepancies cancelling each other out. Overall, the differences are less than $1 \%$, except in the case of insufficient GCPs where the errors are much more significant; therefore, UAV photogrammetry is suitable for calculating volumes of large-scale earthworks, especially in open pit mines where the tolerances are larger.

Future improvements in determining the earthworks accuracy include mounting compact mobile laser scanning systems (Julge, Ellmann, Vajakas, \& Kolka, 2016; Julge, Vajakas, \& Ellmann, 2017) on unmanned aerial vehicles. Laser scanning data processing is faster than photogrammetry, and laser beams penetrate vegetation. Laser scanning is performed in poor light conditions and at night. Laser scanning is also generally not influenced by the colour and texture of the measured object, whereas photogrammetry on monotone and flat objects will

Table 2. The volume of the embankment calculated with different methods and volume differences compared to the Global Navigation Satellite System results

\begin{tabular}{|c|c|c|c|c|}
\hline \multirow{2}{*}{ Input data } & \multirow{2}{*}{$\begin{array}{c}\text { Volume, } \\
\mathrm{m}^{3}\end{array}$} & \multicolumn{3}{|c|}{ Volume difference, } \\
\hline & & $\%$ & $\mathbf{m}^{3}$ & $7 \mathrm{~m}^{3}$ truckloads \\
\hline Global Navigation Satellite System points & 16950.8 & - & - & - \\
\hline Octocopter, flight height $60 \mathrm{~m}$ & 17095.9 & $0.9 \%$ & 145.1 & 21 \\
\hline Octocopter, flight height $100 \mathrm{~m}$ & 17079.0 & $0.8 \%$ & 128.2 & 19 \\
\hline Basic unmanned aerial vehicle & 16922.0 & $-0.2 \%$ & 28.8 & 5 \\
\hline Octocopter, only four ground control points & 17932.7 & $5.8 \%$ & 981.9 & 141 \\
\hline
\end{tabular}


fail. However, the investment into laser scanning technology with the sole purpose of determining the volumes of earthworks has not been economically feasible.

\section{Conclusions}

In this contribution, the suitability of unmanned aerial vehicle photogrammetry for measuring road construction earthworks was analysed. The results were compared to GNSS reference data. Root mean square error of $5.7 \mathrm{~cm}$ was achieved with an unmanned aerial vehicle that was carrying a high-quality camera. Although it is not within the $5 \mathrm{~cm}$ accuracy required by the Estonian Road Administration, it is close to the goal set. Some of the discrepancies were caused by the lack of detail of the Global Navigation Satellite System data. Therefore, theoretically with careful data collection and processing techniques the required $5 \mathrm{~cm}$ accuracy for unmanned aerial vehicle surveys could be achieved.

It is essential to use a good quality camera and an unmanned aerial vehicle that carries the payload and execute a predetermined flight plan. A sufficient number of evenly distributed ground control points are vital for achieving good results. Lower than $100 \mathrm{~m}$ flight heights do not significantly improve the overall accuracy of results but yield a better acquisition of some finer surface details.

Unmanned aerial vehicle photogrammetry is a fast and convenient way of measuring and calculating volumes of earthworks. The unmanned aerial vehicle estimated volumes enable a realistic assessment of the cost of the material and labour used for the road embankment earthworks. With proper equipment and methodology, good results are achieved. Besides measuring road structures, the unmanned aerial vehicle photogrammetry can be suited for monitoring open pit mines but can also be used for buildings and natural landscapes. Due to rapid development, unmanned aerial vehicles that carry good quality cameras, as well as photogrammetry software, became more accessible and a viable alternative for many surveying and mapping applications.

\section{Acknowledgements}

Estonian Road Administration is thanked for constructing the Võõbu road construction test site and organizing relevant research.

Two anonymous reviewers are thanked for their constructive comments on the initial version of the manuscript.
Unmanned Aerial Vehicle Surveying for Monitoring

Road Construction Earthworks 


\section{REFERENCES}

Barry, P., \& Coakley, R. (2013). Accuracy of UAV photogrammetry compared with network RTK GPS. Int. Arch. Photogramm. Remote Sens, (2), 27-31.

Bhardwaj, A., Sam, L., Martín-Torres, F. J., \& Kumar, R. (2016). UAVs as remote sensing platform in glaciology: Present applications and future prospects. Remote Sensing of Environment, 175, 196-204. https://doi.org/10.1016/j.rse.2015.12.029

Carrivick, J. L., Smith, M. W., \& Quincey, D. J. (2016). Structure from Motion in the Geosciences. John Wiley \& Sons.

Chen, J., Li, K., Chang, K. J., Sofia, G., \& Tarolli, P. (2015). Open-pit mining geomorphic feature characterisation. International Journal of Applied Earth Observation and Geoinformation, 42, 76-86. https://doi.org/10.1016/j.jag.2015.05.001

Colomina, I., \& Molina, P. (2014). Unmanned aerial systems for photogrammetry and remote sensing: A review. ISPRS Journal of photogrammetry and remote sensing, 92, 79-97. https://doi.org/10.1016/j.isprsjprs.2014.02.013

Julge, K., Ellmann, A., \& Gruno, A. (2014). Performance analysis of freeware filtering algorithms for determining ground surface from airborne laser scanning data. Journal of Applied Remote Sensing, 8(1), 083573. https://doi.org/10.1117/1.JRS.8.083573

Julge, K., Ellmann, A., Vajakas, T., \& Kolka, R. (2016). Initial Tests and Accuracy Assesment of a Compact Mobile Laser Scanning System. International Archives of the Photogrammetry, Remote Sensing \& Spatial Information Sciences, 41. https://doi.org/10.5194/isprsarchives-XLI-B1-633-2016

Julge, K., Vajakas, T., \& Ellmann, A. (2017). Performance analysis of a compact and low-cost mapping-grade mobile laser scanning system. Journal of Applied Remote Sensing, 11(4), 044003. https://doi.org/10.1117/1.jrs.11.044003

Fernández, T., Pérez, J. L., Cardenal, J., Gómez, J. M., Colomo, C., \& Delgado, J. (2016). Analysis of landslide evolution affecting olive groves using UAV and photogrammetric techniques. Remote Sensing, 8(10), 837. https://doi.org/10.3390/rs8100837

Forsman, J., Dettenborn, T., Skepast, P., Mets, M., Olep, M., Ellmann, A., Vallas, I., Tõnts, T., \& Kontson, K. (2016) 2016. Road embankment test sections over soft peat layer, Võõbu, Estonia. Proceedings of the 13th Baltic Geotechnical Conference, 21.-24.9.2016, 302-307. http://doi.org/10.3846/13bsgc.2016.046

Nex, F., \& Remondino, F. (2014). UAV for 3D mapping applications: a review. Applied geomatics, 6(1), 1-15. https://doi.org/10.1007/s12518-013-0120-x

Pajares, G. (2015). Overview and current status of remote sensing applications based on unmanned aerial vehicles (UAVs). Photogrammetric Engineering \& Remote Sensing, 81(4), 281-330. https://doi.org/10.14358/PERS.81.4.281

Raeva, P. L., Filipova, S. L., \& Filipov, D. G. (2016). Volume Computation of a Stockpile-a Study Case Comparing GPS and UAV Measurements in an Open Pit Quarry. International Archives of the Photogrammetry, Remote Sensing \& Spatial Information Sciences, 41. https://doi.org/10.5194/isprsarchives-XLI-B1-999-2016 
Estonian Road Administration (2018). Riigitee nr 2 Tallinn-Tartu-Võru-Luhamaa Kose-Võõbu lõigu ehituse omanikujärelevalve hankedokumendid (Riigihange). (in Estonian)

Rossi, P., Mancini, F., Dubbini, M., Mazzone, F., \& Capra, A. (2017). Combining nadir and oblique UAV imagery to reconstruct quarry topography: Methodology and feasibility analysis. European Journal of Remote Sensing, 50(1), 211-221. https://doi.org/10.1080/22797254.2017.1313097

Sobak, M., Ellmann, A., \& Mill, T. (2015). Terrestrial laser scanning assessment of generalization errors in conventional topographic surveys. Geodesy and Cartography, 41(1), 15-24. https://doi.org/10.3846/20296991.2015.1029755

Tong, X., Liu, X., Chen, P., Liu, S., Luan, K., Li, L., ... \& Hong, Z. (2015). Integration of UAV-based photogrammetry and terrestrial laser scanning for the three-dimensional mapping and monitoring of open-pit mine areas. Remote Sensing, 7(6), 6635-6662. https://doi.org/10.3390/rs70606635

Turner, D., Lucieer, A., \& De Jong, S. M. (2015). Time series analysis of landslide dynamics using an unmanned aerial vehicle (UAV). Remote Sensing, 7(2), 1736-1757. https://doi.org/10.3390/rs70201736

Westoby, M. J., Brasington, J., Glasser, N. F., Hambrey, M. J., \& Reynolds, J. M. (2012). 'Structure-from-Motion' photogrammetry: A low-cost, effective tool for geoscience applications. Geomorphology, 179, 300-314.

https://doi.org/10.1016/j.geomorph.2012.08.021 